Vladimir J. Karanović

\title{
LA RECEPCIÓN DE LA NOVELA PICARESCA ESPAÑOLA EN LAS TRADUCCIONES Y LOS TEXTOS CRÍTICO-LITERARIOS EN SERBIA**
}

\begin{abstract}
La novela picaresca española, (sub)género típico español en su fondo, desde sus inicios despertaba un gran interés de los lectores, autores, críticos y las editoriales, no sólo en España, sino en todo el mundo, convirtiéndose con el tiempo en un elemento constitutivo de la literatura universal. El propósito de este artículo es mostrar qué parte del corpus de la novela picaresca española ha sido traducido al serbio y cómo fue recibido en el ámbito crítico de los traductores del español al serbio e hispanistas serbios. Con el fin de dar un panorama completo de la perspectiva de la recepción de un lector o traductor interesado en la materia picaresca, el objeto de análisis serán tanto las traducciones de las novelas picarescas al serbio (sin pretender dar un análisis filológico o valorar la calidad de la traducción) como los textos complementarios de las traducciones realizadas (introducciones o postfacios).
\end{abstract}

Palabras clave: novela picaresca española, traducción literaria, teoría de la recepción, textos crítico-literarios serbios, hispanismo serbio.

\section{Introducción}

El proceso de la traducción de una obra está estrechamente relacionado con la tarea de crítico literario e historiador de literatura, sea dentro del contexto nacional o extranjero.

La primera traducción de una obra literaria es simultáneamente el primer acto crítico de la obra original, que puede tener gran influencia en

\footnotetext{
* vladimir.karanovic@fil.bg.ac.rs

** La versión preliminar y parcial de este artículo fue presentada como ponencia en el VI Simposio Internacional de Hispanistas «Encuentros 2016», celebrado del 22 al 24 de septiembre de 2016 en la Universidad Jaguelónica de Cracovia (Polonia).
} 
la cultura autóctona. En cuando a la traducción, para realizarla, el texto debe producir un considerable impacto al traductor, y aunque se realice una traducción exclusivamente literaria, el traductor también suele ejercer una influencia literaria de mayor importancia (Mančić, 2010: 40).

Explicar el papel y el impacto de la literatura traducida en una literatura nacional autóctona significa responder a las siguientes preguntas: 1) ¿qué es lo que se traduce?, 2) ¿por qué se traduce?, 3) ¿cómo se traduce?, y finalmente 4) ¿qué influencia ejercen las traducciones realizadas? (Janićijević, 1977: 40). Lógicamente, se puede suponer que se traduce lo que acepta cierto ambiente cultural, trátese o no de las razones objetivas o subjetivas. Influyendo a los lectores, la literatura traducida cambia el ambiente literario y la comunidad lectora e intenta explicar su existencia y justificar las obras traducidas, así trasladadas de otras culturas más o menos conocidas (Janićijević, 1997: 44). En efecto, la literatura traducida influye en la literatura nacional, cuya lengua utiliza, en tres niveles principales: ideológico, de contenido y lingüístico-estilístico. El último nivel resulta raro y difícilmente reconocido, pero la literatura traducida frecuentemente ha sido utilizada como medio de las necesidades ideológicas, políticas y culturales favoreciendo sólo la traducción de las obras selectas y útiles para el fin previsto. También, el empleo de los temas y procedimientos literarios sirve para desarrollar la literatura nacional, y es un acompañante obligatorio a la literatura traducida y su integración en la nacional.

La traducción es, en el fondo, un hecho que testimonia la recepción de una obra extranjera en otra literatura nacional. De ahí que el traductor representa el primer eslabón en este proceso o el primer lector interesado, el primer intérprete y evaluador de un escritor extranjero, principalmente ajeno al público nacional autóctono (Bunjak, 1998: 20). La mera elección de la obra traducida, el proceso de la traducción y finalmente la publicación de la obra traducida, llevan un fuerte sello de la recepción (en cierto sentido del concepto).

Wolfgang Iser (apud Selden, Widdowson et al., 1997: 56) destaca que la tarea principal de un crítico literario no es la de explicar el texto como objeto sino la de presentar, explicar y analizar minuciosamente el efecto producido sobre el lector. Al mismo tiempo, una característica inmanente al texto es la posibilidad de ofrecer al lector una gama de lecturas diferentes y posibles.

El propósito de este artículo es mostrar qué parte del corpus de la novela picaresca española ha sido traducido al serbio y cómo ha sido recibido en el ámbito crítico de los traductores del español al serbio y de los hispanistas serbios. Con el fin de dar un panorama completo de la perspectiva de la recepción de un lector o traductor interesado en la materia picaresca, 
LA RECEPCIÓN DE LA NOVELA PICARESCA ESPAÑOLA

EN LAS TRADUCCIONES Y LOS TEXTOS CRÍTICO-LITERARIOS EN SERBIA

el objeto de análisis serán tanto las traducciones de las novelas picarescas al serbio ( $\sin$ pretender dar un análisis filológico o valorar la calidad de la traducción) como los textos complementarios a las traducciones realizadas (introducciones o postfacios).

\section{La novela picaresca española en las traducciones al serbo-croata y al serbio}

La recepción de la novela picaresca española en el ambiente cultural yugoslavo o serbio data de mediados del siglo XX, para ser exactos de 1951, cuando por primera vez al serbo-croata se tradujeron las dos novelas más célebres de este corpus literario, Lazarillo de Tormes ${ }^{l}$ e Historia de la vida del buscón. ${ }^{2}$

En el ambiente cultural serbio la traducción de las novelas picarescas españolas, al igual que los clásicos de la literatura española, tradicionalmente solía ser resultado de un rigor académico y profesional de los tra-

$1 \quad$ Lazarillo de Tormes (1951). Sa španjolskog preveo Jakša Sedmak, za tisak priredio Josip Tabak. Zagreb: Mladost. La misma traducción se reimprimió después con el subtítulo original traducido (Lazarillo de Tormes, Pikarski roman nepoznatog španjolskog autora iz XVI stoljeća (1964). Preveo Jakša Sedmak, za štampu priredio Josip Tabak. Zagreb: Naprijed.), esta vez sin el texto complementario del traductor Jakša Sedmak pero con la versión abreviada en forma anónima bajo el título «Sobre la novela Lazarillo de Tormes» („O romanu Lazarillo de Tormes"). Por su carácter anónimo y la insignificancia para el tema que tratamos, pensamos que este texto no debería ser considerado.

2 Quevedo, F. de (1951). Životopis lupeža. Sa španjolskoga preveo i napomenama propratio Josip Tabak. Zagreb: Novo pokoljenje. Esta edición fue acompañada por un texto titulado «Francisco de Quevedo» (efectivamente la traducción de un capítulo de la publicación Chabás, J. (1933). Historia de la literatura española. Madrid: Joaquín Gil.), que contiene datos esenciales sobre el autor, su vida y obra en general. Por tratarse de un texto traducido de español y no de una creación original de los traductores serbo-croatas, este texto tampoco debería ser objeto de análisis de este artículo. La misma traducción se reimprimió en la edición corregida y reelaborada (Kevedo, F. de (1961). Životopis lupeža. Preveo sa španskog Josip Tabak. Beograd: Izdavačko preduzeće Rad.) en la que el texto anteriormente mencionado y titulado «Francisco de Quevedo» se quedó fuera de la edición, las notas del traductor no las encontramos después de la traducción, sino en las notas a pie de página, y en la parte final del libro encontramos el texto complementario de José Bort Vela, también titulado «Francisco de Quevedo». 
ductores profesionales o de los hispanistas, que desde los mediados de los años setenta del siglo XX se habían licenciado en Filología Hispánica en el Grupo de Lengua y Literatura Españolas y posteriormente en la Cátedra de Estudios Ibéricos de la Facultad de Filología de Belgrado. El primer paso en este camino lo realizó Jasna Stojanović, quien en 1995 terminó y publicó la primera traducción serbia de la novela picaresca española, con el título completo de la obra original: La vida de Lazarillo de Tormes, de sus fortunas y adversidades (Život Lazarčića sa Tormesa, njegove zgode i nezgode) ${ }^{3}$. Esta traducción contiene numerosas notas a pie de página, que sirven para informar al lector interesado sobre el ambiente histórico, social, literario, mientras que a los hispanistas en formación o a los hispanistas involucrados en este tema les puede ayudar a interpretar y entender fácilmente el texto clásico español. Además, esta edición contiene una bibliografía de las ediciones españolas del libro en cuestión, pero también una bibliografía selecta de los estudios literarios dedicados al tema de la picaresca. Otra de las novedades es el hecho de que la traducción fue apoyada por la Dirección General del Libro, Archivos y Bibliotecas del Ministerio de Cultura de España, institución que había financiado la publicación no solo de todas las novelas picarescas traducidas al serbio, objeto de investigación de este artículo, sino las traducciones de un considerable número de clásicos españoles, publicadas por las editoriales serbias con reducido volumen de producción anual.

Después de la traducción de la primera novela picaresca al serbio, entre los hispanistas serbios despierta el interés este subgénero introducido al ambiente cultural serbio y regional. En este sentido es muy significativa la contribución del romanista Radivoje Konstantinović, quien en 2003 publica la primera traducción al serbio de la novela picaresca de Francisco de Quevedo, Historia de la vida del buscón (Životopis pustolova po imenu don Pablos). ${ }^{4}$ Esta obra en 2004 obtuvo el premio de la Fundación «Radoje Tatić», reservado para las traducciones del español y portugués al serbio. La importancia de la novela de Quevedo en la historia de la picaresca española es enorme, tanto por su originalidad como por los juegos con el género del autor y la reivindicación de las fronteras poéticas del

3 Живой Лазарчића са Тормеса, юейове зі̄oge и незі̄oge (1995). Превела са старошпанског језика, поговор, библиографију и белешке сачинила Јасна Стојановић. Београд: Лапис.

4 Кеведо, Ф. де (2003). Живойойис йусйолова йо имену дон Паблос. Превод са шпанског, предговор и напомене Радивоје Константиновић. Београд: Српска књижевна задруга. 
LA RECEPCIÓN DE LA NOVELA PICARESCA ESPAÑOLA

EN LAS TRADUCCIONES Y LOS TEXTOS CRÍTICO-LITERARIOS EN SERBIA

subgénero. Parece que este conocimiento y el rigor profesional han sido los elementos cruciales para la inspiración a seguir con el tratamiento de la picaresca española mediante las traducciones entre los hispanistas y los traductores serbios del momento, así que muy pronto, en 2004, la hispanista y traductora Aleksandra Mančić publicó su versión de la traducción de la misma novela, esta vez con el título original completo: Historia de la vida del buscón, llamado don Pablos, ejemplo de vagamundos y espejo de tacaños (Žitije vrdalame po imenu don Pablos, primernog probisveta, slike i prilike mufljuza $)^{5}$. La aparición de una traducción más de la misma obra abrió un gran abanico de posibilidades para los hispanistas y el público interesado encaminado a valorar y analizar esta valiosa obra de la prosa del barroco español desde varias perspectivas, especialmente para poder comparar dos visiones e interpretaciones textuales realizadas por traductores e hispanistas prestigiosos, cuya obra ha sido reconocida durante su vida profesional con relevantes premios para la traducción y ensayística en Serbia. De ese modo surgió la base fundamental para los estudios y análisis comparativos, iniciados en los textos ensayísticos y artículos científicos.

Después de la publicación de la primera traducción de la novela picaresca española, Lazarillo de Tormes (1995), y dos versiones de la novela Historia de la vida del buscón (2003 y 2004), los lectores y el público serbios, los hispanistas, los comparatistas y todos los aficionados y literatos quedaron familiarizados con los representantes más destacados de la novela picaresca. Sin embargo, la abundancia y la importancia de este corpus literario no permite a los hispanistas que cese el interés por las nuevas traducciones, siendo unos de los motivos el de no privar la literatura serbia traducida de numerosas obras esenciales y casi igualmente importantes de la picaresca española.

La idea de continuar yendo por este camino ha sido aliciente para realizar la traducción de la obra La hija de Celestina (Selestinina kći) ${ }^{6}$ de Alonso Jerónimo de Salas Barbadillo, publicada en 2016 y traducida por el quien firma este artículo. Esta, tercera obra de la novela picaresca traducida al serbio, tiene muchos elementos originales y representa la primera novela picaresca traducida al serbio del llamado «grupo de la novela picaresca femenina», donde el protagonismo lo tienen las mujeres-pícaras.

5 Kevedo, F. de (2004). Žitije vrdalame po imenu don Pablos, primernog probisveta, slike i prilike mufjuza. Prevela Aleksandra Mančić. Beograd: Izdavačko preduzeće Rad.

6 Salas Barbadiljo, A. H. de (2016). Selestinina kći. Prevod sa španskog, pogovor i beleške Vladimir Karanović. Beograd: Partenon, Bibliotheca Hispania. 


\section{La novela picaresca española en los textos complementarios (introducciones y postfacios)}

Consideramos que es de gran importancia el análisis de los textos críticos, que acompañan las traducciones de las novelas picarescas al serbio. Se trata de textos escritos por los hispanistas o especialistas en temas de las literaturas románicas, o sea, lectores informados, intérpretes y críticos efectivamente «ideales», especialmente por sus competencias, nivel informativo y el alto grado de las expectativas en cuanto a la obra original. Estos textos nos pueden servir para obtener informaciones sobre el contexto del traductor, sus motivos de empezar con el trabajo realizado, sobre el público meta y sobre el ambiente cultural que deja la obra traducida en su territorio literario.

En su texto complementario que acompaña la primera traducción de Lazarillo de Tormes al serbo-croata ${ }^{7}$, bajo el título «Lazarillo de Tormes», el traductor Jakša Sedmak explica brevemente el contexto histórico y social de la época vigente. Además, trata los temas generales de la primera novela picaresca, como la cuestión de la autoría, el contexto literario español y la importancia e impacto que la primera novela picaresca española habían ejercido en el ámbito nacional español de su tiempo. De ahí su realismo subrayado en la segunda parte de este breve texto, como la característica más importante y el rasgo diferencial de otros subgéneros novelescos españoles de la época renacentista. Precisamente el aspecto realista será el elemento más estudiado de la picaresca española. A pesar de su breve extensión y modesta aportación científica, se trata de un texto esencial, informativo y adaptado a los ambientes cultural y literario yugoslavos, pero sin los detalles que se podrían esperar de la publicación de la primera novela picaresca española en serbo-croata, desconocida hasta el momento.

Después de casi 45 años la hispanista serbia Jasna Stojanović enriquece su edición de la primera traducción de esta novela al serbio con un texto complementario bajo el título «Postfacio» ${ }^{8}$. A diferencia de los textos añadidos a la traducción serbo-croata anterior, éste resulta más minucioso, detallado y elaborado por una hispanista obviamente involucrada en el tema. Tratando diferentes aspectos principales tan frecuentes en la litera-

7 Sedmak, J. (1951). Lazarillo de Tormes. In Lazarillo de Tormes, sa španjolskog preveo Jakša Sedmak, za tisak priredio Josip Tabak (pp. 73-74). Zagreb: Mladost.

8 Стојановић, J. (1995). Поговор. In Живой Лазарчића са Тормеса, юейове зйоgе u незі̄oge, превела са старошпанског језика, поговор, библиографију и белешке сачинила Јасна Стојановић (pp. 69-77). Београд: Лапис. 
LA RECEPCIÓN DE LA NOVELA PICARESCA ESPAÑOLA

EN LAS TRADUCCIONES Y LOS TEXTOS CRÍTICO-LITERARIOS EN SERBIA

tura crítica, la autora logra dar explicaciones más competentes e informar al lector interesado sobre las tendencias modernas y vigentes en cuanto a la crítica y la investigación científica. La importancia de las llamadas «cuestiones palpitantes» del Lazarillo de Tormes ha resultado muy universal, porque las dudas expresadas en este texto (la autoría, los elementos picarescos, los motivos predominantes, el análisis psicológico del protagonista, etc.) actualmente siguen despertando una gran atención de los hispanistas por todo el mundo. Las aportaciones más importantes y originales de este texto complementario son la cuestión de las raíces folklóricas de la obra, el análisis narratológico y varios juicios críticos que ejerce la autora manejando las citas bibliográficas relevantes o revalorizando y reivindicando los postulados de los hispanistas extranjeros, expertos en esta materia. Los últimos párrafos del texto tratan tanto el proceso de la traducción de la primera novela picaresca española como su presencia en otros países europeos y su impacto en el arte universal.

El primer texto crítico sobre la obra de Quevedo escrito en serbo-croata es el titulado «Francisco de Quevedo» ${ }^{9}$ de José Bort Vela, primer lector de español en la Universidad de Belgrado, activo a mediados del siglo XX. Este texto consta de una breve presentación de datos biográficos del autor barroco español y prácticamente puede ser útil solo a los lectores serbios sin conocimientos previos de la literatura española y la del Siglo de Oro español. El realismo como característica esencial de la literatura española en general, el espíritu satírico del autor, el juego con los elementos picarescos, son algunos temas predominantes en la parte más concreta de este sencillo texto.

En Serbia, el momento crucial en la recepción y la traducción de la novela picaresca de Francisco de Quevedo fue la publicación de su primera traducción en 2003. En su edición, el traductor y romanista eminente Radivoje Konstantinović rompió con la tradición predominante en las traducciones anteriores de acompañarlas de unos textos breves, superficiales y generales, creando un minucioso e interesante estudio de la obra quevedesca y de varios aspectos esenciales de la novela picaresca traducida. Su texto titulado «Introducción» ${ }^{10}$ guarda numerorsos datos biográficos del

9 Bort Vela, H. (1961). Fransisko de Kevedo. In F. de Kevedo, Životopis lupeža, preveo sa španskog Josip Tabak (pp. 157-160). Beograd: Izdavačko preduzeće Rad.

10 Константиновић, Р. (2003). Предговор. In Ф. де Кеведо, Живойойис ӣусииолова йо имену gон Паблос, превод са шпанског, предговор и напомене Радивоје Константиновић (pp. VII-XVII). Београд: Српска књижевна задруга. 
autor español, pero tambien contiene varias valoraciones de su obra, aspecto original y útil para el proceso de la recepción de la obra picaresca en nuestro ámbito cultural. Además, en algunos fragmentos del texto Konstantinović destaca el papel político que tenía Quevedo durante un período de su vida. Así el lector serbio interesado tiene la posibilidad de saber algo más de lo ya expuesto en los textos anteriores y de profundizar considerablemente sus conocimientos de la materia. El autor del texto insiste en la importancia de la novela picaresca dentro del corpus picaresco en general, destacando que El Buscón es la obra más famosa de Quevedo, pero a la vez la novela española más popular y más conocida después de Don Quijote. Resulta original e interesante el paralelo subrayado entre la época de Quevedo y la nuestra, símbolo de crisis personal y colectiva.

En la segunda traducción de la novela quevedesca, realizada por la hispanista y una de las traductoras más fructíferas Aleksandra Mančić solo un año después, encontramos un texto adicional bajo el título «Sobre el escritor y la obra ${ }^{11}$. Además de datos frecuentes en la literatura crítica sobre el tema de la novela quevedesca, la autora destaca la originalidad de esta obra, su mero marco picaresco, utilizado como medio para presentar los numerosos postulados ideológicos del escritor aficionado a la sátira y la crítica social. La visión grotesca de la realidad, los elementos carnavalescos y escatológicos, la parodia de la religiosidad, son solo algunos temas de este detallado estudio. Tal vez la mayor aportación de este texto es el breve análisis de varios manuscritos de la obra original y la justificación de la traductora por la elección del llamado «manuscrito B» de la obra original quevedesca, fijado por Edmond Cros. Asimismo, en el último párrafo encontramos la explicación de la traductora por no haber puesto los comentarios en las notas a pie de página, destacando que el procedimiento quevedesco se había basado en la conceptualización abstracta, alejada de la realidad y de lo cotidiano. El fin de la traductora obviamente ha sido presentar o ilustrar los elementos crudos y fríos del estilo novelesco de Francisco de Quevedo.

Hasta ahora la última traducción de una novela picaresca española, al mismo tiempo la primera del corpus de la picaresca femenina, está

11 Mančić, A. (2004). O piscu i delu. In F. de Kevedo, Žitije vrdalame po imenu don Pablos, primernog probisveta, slike i prilike mufjuza, prevela Aleksandra Mančić (pp. 141-147). Beograd: Izdavačko preduzeće Rad. 
LA RECEPCIÓN DE LA NOVELA PICARESCA ESPAÑOLA

EN LAS TRADUCCIONES Y LOS TEXTOS CRÍTICO-LITERARIOS EN SERBIA

acompañada por comentarios que facilitan la lectura del texto y un texto complementario en forma de postfacio titulado «La reivindicación de los límites del género picaresco y la ascendencia de las pícaras: La hija de Celestina de Alonso Jerónimo de Salas Barbadillo» ${ }^{12}$. Este texto representa el único estudio sintético y detallado sobre varios aspectos esenciales de la obra, hasta el presente prácticamente desconocida en Serbia. El autor del texto presenta brevemente los escasos datos biográficos conocidos sobre el escritor del Siglo de Oro español, su obra completa y el contexto cultural y social que lo rodeaba. La mayor aportación del texto reside en la segunda parte, como estudio minucioso y polémico sobre los límites del género picaresco y la originalidad de la obrita, obviamante a medio camino entre la novela picaresca y la novela corta (cortesana). Los últimos párrafos intentan recordar al lector la escasa recepción que la traducción de la novela picaresca española en Serbia ha recibido, tanto por la ausencia de los hispanistas interesados en este tema (con la excepción de Jasna Stojanović, Radivoje Konstantinović y Aleksandra Mančić) como por el problemático contexto editorial que acompaña el proceso de publicación de las traducciones del español. De ahí, el texto abre camino para el desarrollo de los estudios de la recepción de la picaresca española en Serbia e intenta cuestionar o enfatizar los postulados tradicionales de la actividad de los hispanistas en este campo.

\section{Conclusiones}

La novela picaresca española tiene una larga tradición en cuanto a su presencia y recepción en al ámbito cultural, inicialmente yugoslavo, y actualmente serbio. Las primeras novelas traducidas al serbo-croata a mediados del siglo XX no despertaron un gran interés de los lectores interesados, posiblemente por la falta de conciencia y saberes formales del público yugoslavo sobre el origen de la picaresca. Fuera del ambiente académico, el impacto de este subgénero en la literatura serbia contemporá-

12 Karanović, V. (2016). Preispitivanje granica pikarskog žanra i uspon pikarki: Selestinina kći Alonsa Heronima de Salas Barbadilja. In A. H. de Salas Barbadiljo, Selestinina kći, prevod sa španskog, pogovor i beleške Vladimir Karanović (pp. 97-118). Beograd: Partenon, Bibliotheca Hispania. 
nea, después de las publicaciones de las primeras traducciones al serbio, ha sido escaso. ${ }^{13}$ Por falta de contactos culturales españoles y serbios, por un lado, y un fuerte impacto de otras literaturas europeas en Serbia, por otro, la recepción de la literatura picaresca en un ambiente serbio más general posiblemente se ha realizado mediante las traducciones de las novelas picarescas francesas, inglesas o alemanas, que tradicionalmente tenían un foco diferente y original, apartando de vez en cuando la obra literaria del original español. ${ }^{14}$ De ese modo, generalmente todo lo que hallemos de lo picaresco en las obras de los escritores serbios representará una posible influencia indirecta, ejercida mediante el puente establecido entre España y otros países europeos hace ya varios siglos.

La recepción de las novelas picarescas españolas mediante las traducciones obviamente es resultado de los esfuerzos personales de los romanistas y profesores universitarios de Croacia (en la primera fase de la recepción, en el ámbito cultural yugoslavo), aunque la situación cambia radicalmente y este proceso evoluciona considerablemente en el ámbito cultural serbio después de la fundación del Grupo de Lengua y Literatura

13 Una prueba valiosa de esta afirmación reside en el hecho de que escasos novelistas serbios de varias épocas, del realismo a la época contemporánea, se refieren en sus novelas a la picaresca exclusivamente española. Sin embargo, los elementos picarescos en la literatura serbia aparecen en varias novelas de Jakov Ignjatović, Simo Matavulj, Dragoslav Mihailović, Siniša Živković, Laslo Blašković, Aleksandar Gatalica, etc. Aunque la mayoría de las novelas, por ejemplo, de los escritores contemporáneos serbios llevan el subtítulo «novela picaresca», suelen utilizar solo algunos aspectos y/o procedimientos típicamente picarescos: la estructura itinerante, el personaje marginado (de diferentes maneras), la moralidad cuestionada del protagonista, etc. La mayoría de ellos crea unas obras de mero marco picaresco, privadas de todo el espíritu picaresco y del esquema picaresco claramente preestablecido. Además, la contemporaneidad de la trama novelesca de la gran parte de estas obras impide el empleo de todo el potencial ideológico picaresco español, característico para los tiempos lejanos y un marco histórico concreto y diferente del actual. Es más, creemos que sería adecuado hablar solo de la interpretación del marco picaresco de los novelistas contemporáneos serbios y del eco lejano picaresco en sus obras y no de la influencia y la recepción directas, imposibilitadas por razones ya expuestas y elaboradas.

Al no ser este tema el objeto de análisis del presente artículo, lo dejamos abierto e inconcluso y puede resultar interesante para futuras investigaciones comparativas.

14 Varias novelas picarescas europeas fueron traducidas al serbio durante el siglo XX y estaban fácilmente disponibles a los lectores y escritores serbios: Simplicissimus de Hans Jacob Christoffel von Grimmelshausen, Gil Blas de Lesage, Moll Flanders de Daniel Defoe, etc. 
LA RECEPCIÓN DE LA NOVELA PICARESCA ESPAÑOLA

EN LAS TRADUCCIONES Y LOS TEXTOS CRÍTICO-LITERARIOS EN SERBIA

Españolas en 1971 en la Universidad de Belgrado. En las últimas tres décadas se han traducido al serbio tres novelas picarescas españolas: Lazarillo de Tormes (1995), Historia de la vida del buscón (2003 y 2004) y La hija de Celestina (2016). Hay una desproporción entre el número de los libros traducidos del español al serbio en general y el número de las novelas picarescas traducidas, especialmente si tenemos en cuenta el volumen del corpus literario en cuestión (más de veinte libros picarescos importantes, publicados en España durante la primera mitad del siglo XVII). La publicación de las traducciones de los clásicos españoles, y consecuentemente de la picaresca española, siempre ha sido y sigue siendo fruto de la colaboración entre los traductores y las editoriales serbias, cuyas tiradas de las traducciones del español son mínimas, por no tratarse de libros comerciales, un requisito tan imprescindible en la política editorial contemporánea.

En cuanto a la actividad crítico-literaria, especialmente la realizada mediante los textos complementarios, acompañantes de las traducciones, podemos concluir que está emprendiéndose simultáneamente con las ediciones originales o reimpresas y testimonia sobre el considerable grado de percepción de la importancia de las traducciones publicadas y del papel que las introducciones y postfacios tienen en la interacción con los lectores dentro de la literatura traducida. Estos textos complementarios resultan intencionalmente equilibrados, a medio camino entre la necesidad de informar a un gran círculo de lectores sobre los estudios generales de la obra en cuestión y el deseo palpitante de interesar y animar a los hispanistas y otros lectores «ideales» para contribuir al desarrollo de los estudios sistemáticos de la picaresca española en el ambiente cultural y académico serbio.

\section{Literatura}

Traducciones de la novela picaresca española al serbo-croata y al serbio:

\section{Lazarillo de Tormes}

Lazarillo de Tormes (1951). Sa španjolskog preveo Jakša Sedmak, za tisak priredio Josip Tabak. Zagreb: Mladost.

Lazarillo de Tormes, Pikarski roman nepoznatog španjolskog autora iz XVI stoljeća (1964). Preveo Jakša Sedmak, za štampu priredio Josip Tabak. Zagreb: Naprijed. 
Život Lazarčića sa Tormesa, njegove zgode $i$ nezgode (1995). Prevela sa starošpanskog jezika, pogovor, bibliografiju i beleške sačinila Jasna Stojanović. Beograd: Lapis.

Historia de la vida del buscón

Quevedo, F. de (1951). Životopis lupeža, sa španjolskoga preveo i napomenama propratio Josip Tabak. Zagreb: Novo pokoljenje.

Quevedo, F. de (1961). Životopis lupeža, preveo sa španskog Josip Tabak. Beograd: Izdavačko preduzeće Rad.

Kevedo, F. de (2003). Životopis pustolova po imenu don Pablos, prevod sa španskog, predgovor i napomene Radivoje Konstantinović. Beograd: Srpska književna zadruga.

Kevedo, F. de (2004). Žitije vrdalame po imenu don Pablos, primernog probisveta, slike i prilike mufluza, prevela Aleksandra Mančić. Beograd: Izdavačko preduzeće Rad.

\section{La hija de Celestina}

Salas Barbadiljo, A. H. de (2016). Selestinina kći. Prevod sa španskog, pogovor i beleške Vladimir Karanović. Beograd: Partenon, Bibliotheca Hispania.

\section{Estudios, artículos y textos complementarios:}

Bort Vela, H. (1961). Fransisko de Kevedo. In F. de Kevedo, Životopis lupeža, preveo sa španskog Josip Tabak (pp. 157-160). Beograd: Izdavačko preduzeće Rad.

Bunjak, P. (1998). O pitanju istorije recepcije strane književnosti. Književna istorija, časopis za nauku o književnosti, XXX (104), 5-26.

Janićijević, J. (1977). Prevodna književnost. Kultura, 38, 40-50.

Karanović, V. (2016). Preispitivanje granica pikarskog žanra i uspon pikarki: Selestinina kći Alonsa Heronima de Salas Barbadilja. In A. H. de Salas Barbadiljo, Selestinina kći, prevod sa španskog, pogovor i beleške Vladimir Karanović (pp. 97-118). Beograd: Partenon, Bibliotheca Hispania.

Konstantinović, R. (2003). Predgovor. In F. de Kevedo, Životopis pustolova po imenu don Pablos, prevod sa španskog, predgovor i napomene Radivoje Konstantinović (pp. VII-XVII). Beograd: Srpska književna zadruga.

Mančić, A. (2004). O piscu i delu. In F. de Kevedo, Žitije vrdalame po imenu don Pablos, primernog probisveta, slike i prilike mufljuza, prevela Aleksandra Mančić (pp. 141-147). Beograd: Izdavačko preduzeće Rad. 
LA RECEPCIÓN DE LA NOVELA PICARESCA ESPAÑOLA EN LAS TRADUCCIONES Y LOS TEXTOS CRÍTICO-LITERARIOS EN SERBIA

Mančić, A. (2010). Prevod i kritika. Beograd: Institut za književnost i umetnost. Sedmak, J. (1951). Lazarillo de Tormes. In Lazarillo de Tormes, sa španjolskog preveo Jakša Sedmak, za tisak priredio Josip Tabak (pp. 73-74). Zagreb: Mladost.

Selden, R. \& Widdowson, P. et al. (eds.) (1997). A Reader's Guide to Contemporary Literary Theory. $4^{\text {th }}$ edition. London: Prentice Hall.

Stojanović, J. (1995). Pogovor. In Život Lazarčića sa Tormesa, njegove zgode $i$ nezgode, prevela sa starošpanskog jezika, pogovor, bibliografiju i beleške sačinila Jasna Stojanović (pp. 69-77). Beograd: Lapis.

Владимир Ј. Карановић

\section{Резиме}

\section{РЕЦЕПЦИЈА ШПАНСКОГ ПИКАРСКОГ РОМАНА У ПРЕВОДИМА И КЊИЖЕВНОКРИТИЧКИМ ТЕКСТОВИМА У СРБИЈИ}

Шпански пикарски роман, у основи типично шпанска подврста романа, још од првих изданака заокупљао је пажњу читалаца, аутора, критичара и издавачких кућа не само у Шпанији, већ широм света, те с временом постаје и веома битан и неизоставан део светске књижевне баштине. Циљ овог чланка је да се представи онај део корпуса шпанских пикарских романа који је преведен на српски језик, али и да се укаже на елементе рецепције у оквирима културне, преводилачке, књижевнокритичке и хиспанистичке академске средине у Србији. У намери да се понуди један свеобухватан увид у перспективу рецепције овог значајног корпуса шпанских романа међу читаоцима и преводиоцима заинтересованим за дела пикарске тематике, предмет анализе у чланку су како преводи шпанских пикарских романа на српски језик (без намере да се спроведе класична филолошка анализа или вреднује квалитет превода), тако и пропратни текстови, студије српских хиспаниста и(ли) преводилаца (предговори и поговори).

Кључне речи: шпански пикарски роман, књижевно превођење, теорија рецепције, књижевнокритичке студије у Србији, хиспанистика у Србији. 
Vladimir J. Karanović

\section{Summary}

\section{THE RECEPTION OF THE SPANISH PICARESQUE NOVEL IN TRANSLATIONS AND LITERARY STUDIES IN SERBIA}

From its beginnings, the Spanish picaresque novel, a typical Spanish (sub) genre in its basis, aroused a great interest among the readers, authors, critics, and the publishers, not only in Spain but in the whole world. In time, it has become a constitutive element of world literature. The purpose of this article is to show what part of the corpus of the Spanish picaresque novel has been translated into Serbian so far and how it has been received in the field of literary criticism, by translators from Spanish to Serbian and by Serbian Hispanists. In order to give a complete picture of the reception perspective of a reader or a translator interested in the picaresque subject, the object of the analysis will be both the translations of the picaresque novels into Serbian (without attempting to give a philological analysis or to assess the quality of translation) and the complementary texts published along with the translations (introductions or postfaces).

Key words: Spanish picaresque novel, literary translation, reception theory, Serbian literary critical texts, Serbian Hispanism. 